\title{
The use of syndromic surveillance to monitor the incidence of arthropod bites requiring healthcare in England, 2000-2013: a retrospective ecological study
}

\author{
S. NEWITT ${ }^{*}$, A. J. ELLIOT ${ }^{2}$, R. MORBEY ${ }^{2}$, H. DURNALL ${ }^{3}$, M. E. PIETZSCH ${ }^{4}$, \\ J. M. MEDLOCK ${ }^{4}$, S. LEACH ${ }^{4}$ AND G. E. SMITH ${ }^{2}$ \\ ${ }^{1}$ Field Epidemiology Training Programme, Field Epidemiology Service, West Midlands, Public Health England, \\ Birmingham, UK \\ ${ }^{2}$ Real-time Syndromic Surveillance Team, National Infection Service, Public Health England, Birmingham, UK \\ ${ }^{3}$ Royal College of General Practitioners Research and Surveillance Centre, CIRC, London, UK \\ ${ }^{4}$ Emergency Response Department Science \& Technology, Public Health England, Porton Down, Salisbury, \\ Wilts, UK
}

Received 4 September 2015; Final revision 13 February 2016; Accepted 16 March 2016; first published online 12 April 2016

\section{SUMMARY}

Climate change experts predict the number of nuisance-biting arthropods in England will increase but there is currently no known surveillance system in place to monitor or assess the public health impact of arthropod bites. This retrospective ecological study utilized arthropod bites requiring healthcare from five national real-time syndromic surveillance systems monitoring general practitioner (GP) consultations (in-hours and out-of-hours), emergency department (ED) attendances and telephone calls to remote advice services to determine baseline incidence in England between 2000 and 2013 and to assess the association between arthropod bites and temperature. During summer months (weeks 20-40) we estimated that arthropod bites contribute a weekly median of $\sim 4000$ GP consultations, 750 calls to remote advice services, 700 ED and 1300 GP out-of-hours attendances. In all systems, incidence was highest during summer months compared to the rest of the year. Arthropod bites were positively associated with temperature with incidence rate ratios (IRRs) that ranged between systems from 1.03 [95\% confidence interval (CI) $1 \cdot 01-1 \cdot 06$ ] to $1 \cdot 14(95 \%$ CI 1·11-1·16). Using syndromic surveillance systems we have established and described baseline incidence of arthropod bites and this can now be monitored routinely in real time to assess the impact of extreme weather events and climate change.

Key words: Arthropod bite, climate change, mosquito, syndromic surveillance, temperature, tick.

\section{INTRODUCTION}

Arthropods are invertebrates with an exoskeleton, segmented body and joined appendages. The two main classes of medical importance are Insecta (e.g. lice, fleas, bedbugs, flies, bees, mosquitoes) and Arachnida

\footnotetext{
* Author for correspondence: Miss S. Newitt, Public Health England, 6th Floor, 5 St Philip's Place, Birmingham B3 2PW, UK. (Email: sophie.newitt@phe.gov.uk)
}

(e.g. spiders, ticks, mites) which account for more morbidity and mortality worldwide than any other group of venomous creatures [1]. Human-biting arthropods in the UK cause a range of illness from mild irritation and weals to more severe allergic reactions, anaphylactic shock and secondary bacterial infections [2-5] (Table 1). Arthropods are vectors that transmit infections such as Borrelia, Rickettsia, Anaplasma and Louping ill virus to humans [6] and can be particularly sensitive to climatic changes. Climate experts 
Table 1. Details of the types of arthropods in England with their biting phenology (J. M. Medlock, personal communication)

\begin{tabular}{|c|c|c|}
\hline Arthropod group & No. species and principal nuisance species & Biting phenology \\
\hline $\begin{array}{l}\text { Mosquitoes (Diptera: } \\
\text { Culicidae) }\end{array}$ & $\begin{array}{l}\text { 34; Aedes detritus, Culex modestus, Anopheles } \\
\text { atroparvus (coastal), Culex molestus, Culiseta } \\
\text { annulata (urban), Aedes cantans, Aedes punctor } \\
\text { (woodland), Coquillettidia richiardii, Aedes } \\
\text { cinereus, Aedes caspius (ditch, ponds, wet } \\
\text { grassland) }\end{array}$ & $\begin{array}{l}\text { Most mosquito species peak in summer (July- } \\
\text { September), although some species will bite } \\
\text { earlier and later in the season }\end{array}$ \\
\hline Ticks (Acari: Ixodidae) & $\begin{array}{l}\text { 21; principal human-biting species is the deer/ } \\
\text { sheep tick (Ixodes ricinus) }\end{array}$ & $\begin{array}{l}\text { Different stages of Ixodes ricinus have } \\
\text { different phenology. The stage most } \\
\text { commonly found on humans is the nymph } \\
\text { which peaks in activity in spring (April-June) } \\
\text { then to a lesser degree in early autumn. They } \\
\text { are not as active in hot summers }\end{array}$ \\
\hline $\begin{array}{l}\text { Blackflies (Diptera: } \\
\text { Simuliidae) }\end{array}$ & $\begin{array}{l}\text { 35; Blandford fly (Simulium posticatum) and } \\
\text { birch flies (Simulium reptans, S. tuberosum). }\end{array}$ & April-May (Blandford fly) \\
\hline $\begin{array}{l}\text { Horseflies/clegs (Diptera: } \\
\text { Tabanidae) }\end{array}$ & $\begin{array}{l}\text { 30; Notch-horned cleg fly (Haematopota } \\
\text { pluvialis) }\end{array}$ & $\begin{array}{l}\text { May-September. Prefer hot summer days, } \\
\text { biting usually after noon in fields and open } \\
\text { spaces in woods and country roads close to } \\
\text { horses and livestock }\end{array}$ \\
\hline $\begin{array}{l}\text { Culicoides biting midges } \\
\text { (Diptera: } \\
\text { Ceratopogonidae) }\end{array}$ & 47; Highland midge (Culicoides impunctatus) & June-September \\
\hline Fleas (Siphonaptera) & $\begin{array}{l}\text { 60; At least } 10 \text { species reported to bite humans. } \\
\text { Cat flea (Ctenocephalides felis felis), bird flea } \\
\text { (Ceratophyllus gallinae), human flea (Pulex } \\
\text { irritans) }\end{array}$ & $\begin{array}{l}\text { Can be active year-round, but increase in } \\
\text { spring and summer }\end{array}$ \\
\hline $\begin{array}{l}\text { Biting flies (Diptera: } \\
\text { Muscidae) }\end{array}$ & Stable fly (Stomoxys calcitrans) & May-September \\
\hline $\begin{array}{l}\text { Bedbugs (Hemiptera: } \\
\text { Cimicidae) }\end{array}$ & Cimex lectularius & $\begin{array}{l}\text { Activity related to room temperatures, with } \\
\text { increased hatching }>27^{\circ} \mathrm{C} \text {. Highest numbers } \\
\text { of reports in summer/autumn }\end{array}$ \\
\hline $\begin{array}{l}\text { Bees (Hymenoptera: } \\
\text { Apidae) }\end{array}$ & $\begin{array}{l}\text { Honey bees (e.g. Apis mellifera), bumblebees } \\
\text { (e.g. Bombus sp.) }\end{array}$ & June-August \\
\hline $\begin{array}{l}\text { Wasps (Hymenoptera: } \\
\text { Vespidae) }\end{array}$ & Common wasp (Vespula vulgaris) & July-September \\
\hline $\begin{array}{l}\text { Hornets (Hymenoptera: } \\
\text { Vespidae) }\end{array}$ & European hornet (Vespa crabro) & June-August \\
\hline
\end{tabular}

hypothesize that with increases in temperature and changes in land uses, such as the creation and expansion of wetlands and urban green space, the population density of mosquitoes and ticks, and human exposure to them are increasing in the UK [7]. A 2009 survey of environmental health departments in the UK undertaken by the Health Protection Agency found a greater than twofold increase in reports of mosquito nuisance bites during the previous 10 years [8]. The UK has entomological surveillance systems to monitor disease vectors of public health concern (specifically ticks and mosquitoes). However, there is no arthropod bite surveillance to enable the assessment of the public health impact of any observed changes in arthropod activity.
There are few examples of either a national surveillance system or published studies investigating the epidemiology of arthropod bites in Europe. Switzerland has a primary-care sentinel system implemented in 2008 that routinely collects tick bite data [9] and estimated an average annual incidence of 254 general practitioner (GP) consultations/100 000 population during 2008-2011. This incidence is much higher than estimates in a UK study that examined GP consultation data for insect bites and found a mean weekly incidence of 5.4/100 000 population during 19992003 [10]. Survey studies have been conducted in Norway examining the number of blood donors experiencing tick bites [11], and in The Netherlands, 
which found the number of people seen by GPs for tick bites had doubled between 1994 and 2001 [12, 13]. Traditional surveillance systems based on laboratory reports, hospital admission and disease notifications are unsuitable for monitoring arthropod bite activity as only a small percentage of cases require hospital treatment, there are no relevant laboratory tests and reporting of arthropod bites is not required under existing health protection legislation in England [14].

We therefore proposed that syndromic surveillance, the real-time (or near real-time) collection, analysis, interpretation, and dissemination of health-related data to enable the early identification of the impact (or absence of impact) of potential human or veterinary public health threats that require effective public health action [15], could be used for monitoring arthropod bites in England. This type of surveillance includes the monitoring of mild illness in the community that would not usually warrant admission to hospital or laboratory testing through data collected for other purposes. Public Health England (PHE) already has a range of existing syndromic surveillance systems, including those based on GP consultations, emergency department (ED) attendances and calls to remote advice services to routinely monitor syndromes such as influenza-like illness and vomiting and diarrhoea [16].

Consequently, we undertook a retrospective ecological study using syndromic surveillance data to determine baseline incidence of arthropod bites requiring healthcare in England and to assess the association between arthropod bites and temperature between 2000 and 2013.

\section{METHODS}

\section{Data sources}

We used data on arthropod bite indicators from five existing real-time syndromic surveillance systems in England. These included the PHE GP in-hours system that monitors GP consultations during standard hours [data from week 14 (2012), 58\% coverage of England's population], PHE GP out-of-hours system that monitors consultations during weekends, evenings/nights, and public holidays [data from week 1 (2011), 80\% coverage of England's population], PHE ED system that monitors ED attendances [data from week 30 (2010), 16\% coverage of England ED attendances] and the PHE Remote Health Advice system that monitored calls to NHS Direct remote health services [data from week 22 (2005), $100 \%$ coverage of England's population] [16]. We also obtained data from the Royal College of General Practitioners (RCGP) Sentinel GP Surveillance System which monitors GP in-hours consultations and was included due to the longevity of the system [data from week 1 (2000), $\sim 2 \%$ coverage of England's population] [17].

The mean weekly Central England Temperature $\left({ }^{\circ} \mathrm{C}\right)$ was obtained from the UK Meteorological Office Hadley Centre dataset (HadCET) and was used as a measure of surface air temperature [18].

\section{Outcome variable}

The main outcome variable was incidence of arthropod bites. Arthropod bites were defined as GP consultations and ED attendances coded as a bite or sting from an insect, arachnid or non-specified arthropod. Telephone calls to remote advice services were also included as these services provide health advice on receipt of a call about symptoms relating to bites and stings.

Bites and stings from crustaceans and all other noninsect and non-arachnid arthropods (where specifically stated to be a non-arachnid) were excluded.

Clinical diagnosis codes relating to arthropod bites were identified and aggregated to develop a composite arthropod bite indicator for each surveillance system. Data were extracted using this indicator with patient's age, sex and geographical location (PHE region), along with appropriate denominator figures.

\section{Data analysis}

We aggregated weekly counts of clinically diagnosed arthropod bites from RCGP and PHE GP in-hours systems to calculate weekly incidence rates $/ 100000$ population based on the patient-registered population in that week as the denominator. Weekly rates may be artificially low during weeks with bank holidays due to general practice closure: to adjust for this effect, weekly rates were scaled up by multiplying by 1.25 during weeks with one bank holiday and 1.67 for weeks containing two bank holidays [19].

For the remaining systems without a defined patient catchment population, the weekly percentage of new arthropod bites out of the total number of coded attendances or calls for that week was calculated.

We excluded NHS Direct data for 2009 from all analysis as the $2009 \mathrm{~A}(\mathrm{H} 1 \mathrm{~N} 1)$ influenza pandemic impacted several indicators resulting in them being 


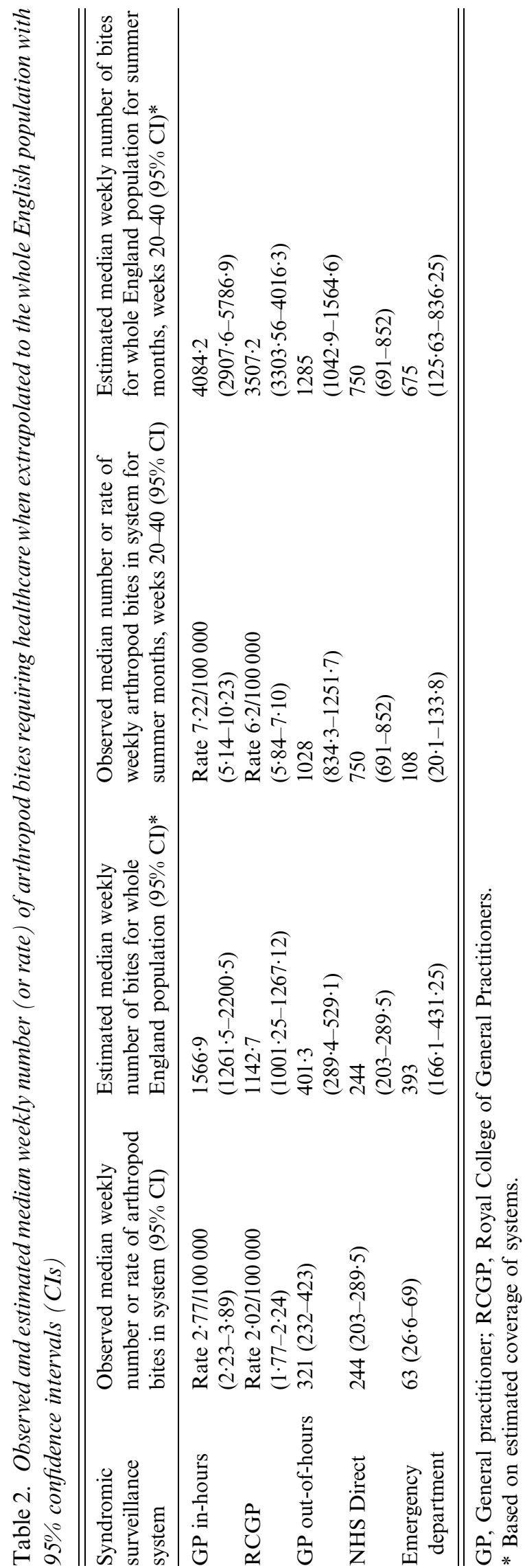

artificially low during this year. The pandemic also led to changes in clinical management algorithms from 2010.

We calculated the median and interquartile range (IQR) of weekly arthropod bite incidence rates/percentages for each system for the overall time period, annually and during the summer weeks. Summer weeks were defined as weeks 20-40 (mid-May to late September).

We calculated incidence rate ratios (IRRs) with 95\% confidence intervals (CIs) to compare arthropod bite incidence between the summer weeks and the rest of the year, males and females, age groups (0-4, $5-14,15-24,25-44,45-64, \geqslant 65$ years) and PHE regions. PHE has four regions (North, Midlands \& East, London, South) whose boundaries are coterminous with those of the NHS Commissioning Board and the Department for Communities and Local Government's resilience hubs.

Based on the known population coverage of each surveillance system, we extrapolated the observed arthropod bite incidence to estimate the weekly number of arthropod bite consultations for the entire population of England with 95\% CIs.

We used negative binomial regression to assess the relationship between arthropod bites and temperature for each system. The time-series components; sequential week and month were included in the model to take account of longer term trends and seasonality in the data. IRR and 95\% CIs were calculated. Analysis was performed using Stata v. 12 (StataCorp, USA).

\section{Ethical approval}

Ethical approval was not required for this study.

\section{RESULTS}

The incidence of arthropod bites for each system is given in Table 2. The median weekly rate of GP consultations for arthropod bites for the PHE GP in-hours system was $2 \cdot 77 / 100000$ population (IQR 1.29-7·10) and for the RCGP system 2·02/100 000 (IQR 0·80-5·26). Arthropod bites accounted for a median of $0 \cdot 35 \%$ of weekly GP out-of-hours coded attendances (IQR 0.13-0.94), 0.33\% of weekly NHS Direct calls (IQR 0.12-0.89) and 0.24\% of weekly ED attendances (IQR 0.15-0.34).

In all systems, arthropod bite incidence was highest during summer months compared to the rest of the year; IRRs ranged between systems from $2.53(95 \%$ CI 2.17-2.94) in the ED system to 6.07 (95\% CI 5.51-6.69) in the RCGP system. Incidence peaked 


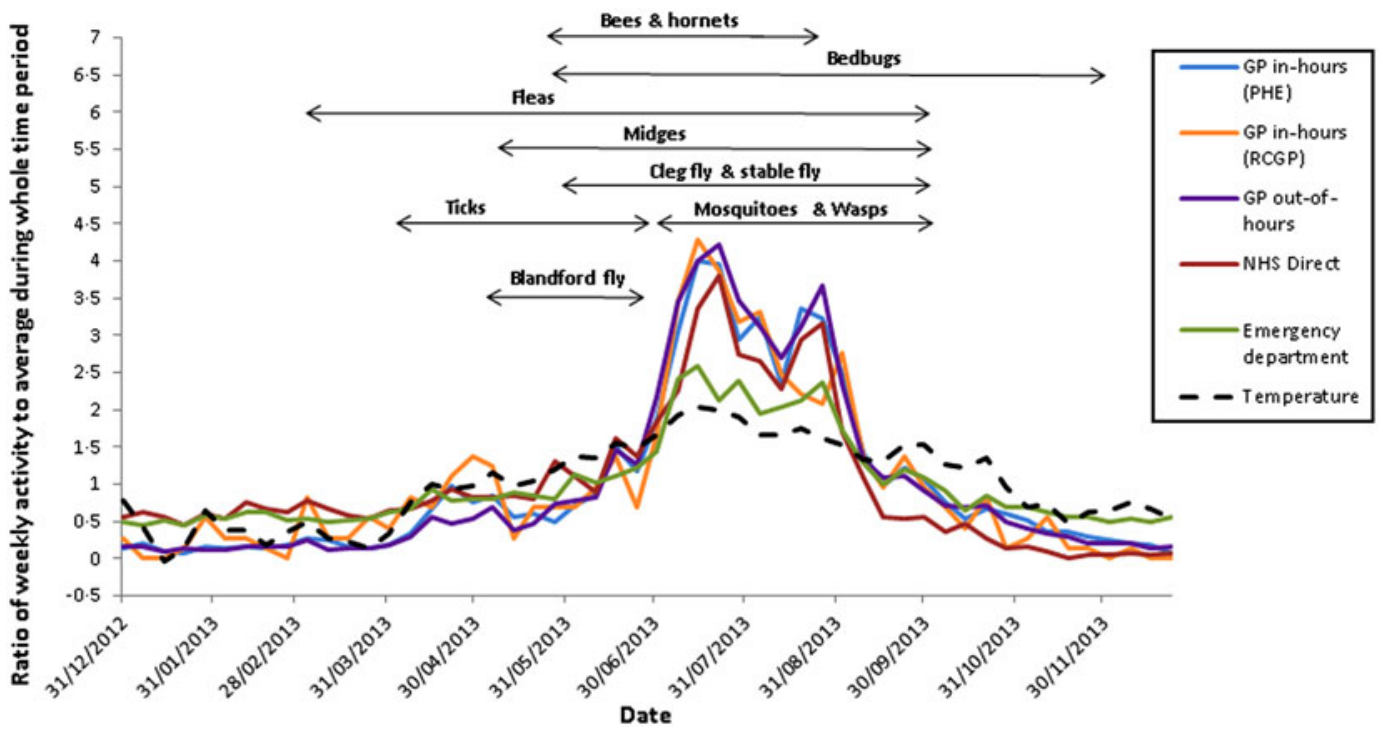

Fig. 1. Ratio of weekly arthropod bite activity to the average activity for 2013 for each syndromic surveillance system and temperature, with biting phenology of arthropods in England.

annually between weeks 27 and 36 (July to early September) as shown in Figure 1.

There were statistically significant differences in arthropod bite incidence by sex in four of the five systems. In the GP in-hours, RCGP and GP out-of-hours systems, females were significantly more likely to consult for an arthropod bite than males [IRR 1.85 (95\% CI 1.79-1.91), IRR1.93 (95\% CI 1.88-2.00), IRR 1.13 $(95 \%$ CI $1 \cdot 12-1 \cdot 15)$, respectively]. In the NHS Direct system, calls for an arthropod bite were significantly lower for females than males (IRR 0.97, 95\% CI 0.96-0.98).

Arthropod bite incidence varied by age group across the systems. The highest incidence was in the 45-64 years age group for the RCGP (rate 4.18/100 000 population), GP out-of-hours ( $1.0 \%$ of attendances) and ED ( $0 \cdot 33 \%$ of attendances) systems. The incidence in the 45-64 years age group was significantly higher than for those aged $0-4$ years across the three systems [IRR $4 \cdot 18$ (95\% CI $1 \cdot 46-1 \cdot 69)$, IRR $5 \cdot 15$ (95\% CI $4 \cdot 99-5 \cdot 32)$, IRR $2 \cdot 13$ (95\% CI 1.99-2.30), respectively]. In the PHE GP in-hours system and NHS Direct system, incidence was highest in 5-14 years age group (rate 5.58/100 000 population) and significantly higher than in the $0-4$ years age group (IRR $1 \cdot 25,95 \% \mathrm{CI} 1 \cdot 16-1 \cdot 35$ ) and $0 \cdot 88 \%$ of calls (IRR $2 \cdot 70,95 \%$ CI $2 \cdot 65-2 \cdot 76$ ).

Statistically significant differences were observed between incidence in the PHE regions South, Midlands \& East, and London compared to the North region. However, there was no consistency across the systems as to which region had the highest incidence.
Table 3. Univariable negative binomial regression for the association between arthropod bite indicators and temperature for each syndromic surveillance system, England

\begin{tabular}{|c|c|c|c|}
\hline \multirow[b]{2}{*}{ Syndromic surveillance system } & \multicolumn{3}{|c|}{ Univariable analysis } \\
\hline & IRR & $95 \% \mathrm{CI}$ & $P$ value \\
\hline \multicolumn{4}{|l|}{ GP in-hours } \\
\hline Temperature & $1 \cdot 21$ & $1 \cdot 19-1 \cdot 22$ & $<0 \cdot 001$ \\
\hline \multicolumn{4}{|l|}{ RCGP } \\
\hline Temperature & $1 \cdot 24$ & $1 \cdot 23-1 \cdot 25$ & $<0 \cdot 001$ \\
\hline \multicolumn{4}{|l|}{ GP out-of-hours } \\
\hline Temperature & $1 \cdot 24$ & $1 \cdot 23-1 \cdot 25$ & $<0 \cdot 001$ \\
\hline \multicolumn{4}{|l|}{ NHS Direct } \\
\hline Temperature & $1 \cdot 21$ & $1 \cdot 19-1 \cdot 22$ & $<0 \cdot 001$ \\
\hline \multicolumn{4}{|l|}{ Emergency department } \\
\hline Temperature & $1 \cdot 09$ & $1 \cdot 08-1 \cdot 11$ & $<0 \cdot 001$ \\
\hline
\end{tabular}

IRR, Incidence rate ratio; CI, confidence interval; GP, General practitioner; RCGP, Royal College of General Practitioners.

Table 2 shows estimates of weekly incidence from extrapolating the observed median weekly number of arthropod bites requiring healthcare in the syndromic surveillance systems to the whole English population.

Univariable analyses (Table 3 ) showed a significant positive association between temperature and attendances/calls for arthropod bites in all systems with IRRs ranging from $1.09(95 \%$ CI $1 \cdot 08-1 \cdot 11)$ for ED attendances to $1.24(95 \%$ CI $1 \cdot 23-1 \cdot 25)$ in the GP out-of-hours and RCGP systems. 
Table 4. Multivariable negative binomial regression model for association between arthropod bite indicators and temperature for each syndromic surveillance system, England

\begin{tabular}{|c|c|c|c|c|c|}
\hline \multirow{2}{*}{$\begin{array}{l}\text { Syndromic } \\
\text { surveillance system }\end{array}$} & \multicolumn{3}{|c|}{ Multivariable analysis* } & \multirow{2}{*}{$\begin{array}{l}\% \text { change in no. of } \\
\text { consultations/calls for } \\
\text { every unit increase }\end{array}$} & \multirow{2}{*}{$\begin{array}{l}\text { No. of weeks compared } \\
\text { in the model }\end{array}$} \\
\hline & IRR & $95 \% \mathrm{CI}$ & $P$ value & & \\
\hline \multicolumn{6}{|l|}{ GP in-hours } \\
\hline Temperature & $1 \cdot 13$ & $1 \cdot 09-1 \cdot 17$ & $<0.001$ & $13 \cdot 2$ & 91 \\
\hline \multicolumn{6}{|l|}{ RCGP } \\
\hline Temperature & $1 \cdot 13$ & $1 \cdot 11-1 \cdot 14$ & $<0 \cdot 001$ & $12 \cdot 8$ & 730 \\
\hline \multicolumn{6}{|l|}{ GP out-of-hours } \\
\hline Temperature & $1 \cdot 14$ & $1 \cdot 11-1 \cdot 16$ & $<0 \cdot 001$ & $13 \cdot 6$ & 156 \\
\hline \multicolumn{6}{|l|}{ NHS Direct } \\
\hline Temperature & $1 \cdot 10$ & $1 \cdot 08-1 \cdot 13$ & $<0 \cdot 001$ & $10 \cdot 3$ & 395 \\
\hline \multicolumn{6}{|l|}{$\begin{array}{l}\text { Emergency } \\
\text { department }\end{array}$} \\
\hline Temperature & $1 \cdot 03$ & $1 \cdot 01-1 \cdot 06$ & $0 \cdot 003$ & $3 \cdot 4$ & 179 \\
\hline
\end{tabular}

IRR, Incidence rate ratio; CI, confidence interval; GP, General practitioner; RCGP, Royal College of General Practitioners. * Model includes time-series components: sequential week and month.

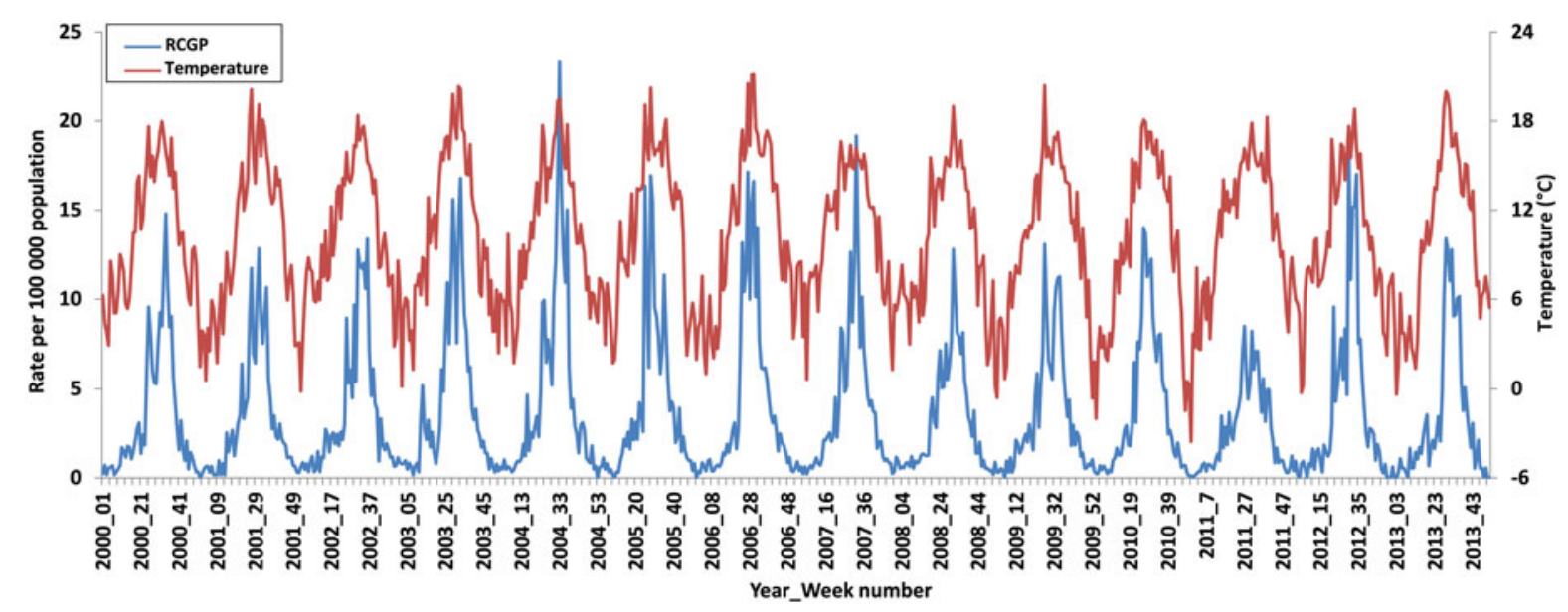

Fig. 2. Time series of the Royal College of General Practitioners (RCGP) syndromic surveillance system arthropod bite consultation rates $/ 100000$ population and temperature $\left({ }^{\circ} \mathrm{C}\right)$, England, 2000-2013.

After adjustment for the time-series component, the positive association with temperature remained statistically significant in all systems (Table 4). We estimate that a 1 degree increase in temperature would result in a simultaneous $3-14 \%$ increase in attendances/calls depending on the system. As an example, Figure 2 shows the temporal relationship between the RCGP system arthropod-bite consultation rates and temperature for England from 2000 to 2013.

\section{DISCUSSION}

Using existing real-time syndromic surveillance systems, we developed arthropod bite indicators to estimate baseline incidence for arthropod bites and produce the most extensive estimate of the public health burden of arthropod bites in England. The findings from our study suggest that patients present to a wide range of healthcare settings for arthropod bites and it is estimated that nationally they account for a weekly median of $\sim 100-1500$ GP in-hours consultations, 400 GP out-of-hours consultations, 250 calls to NHS Direct and 400 ED attendances. Incidence increased up to sixfold during summer months compared to the rest of the year and there was a significant positive association between arthropod bite indicators and temperature for all systems. This is consistent with the summer activity observed from biting phenology of the majority of arthropod groups (Table 1). 
In this study, we found that a $1{ }^{\circ} \mathrm{C}$ increase in seasonal temperature resulted in a simultaneous $3-14 \%$ increase in arthropod bite consultations/calls (depending on the syndromic surveillance system) which could have important implications with the predicted increase in temperature arising from climate change. There are two possible explanations for this observed seasonality in arthropod bite incidence; first, temperature increases observed during summer months may result in changes in human behaviour, for example people spending more time outdoors and wearing summer clothing, which would increase the likelihood of exposure to arthropods [6]. Second, changes in temperature have biochemical, physiological and behavioural effects on arthropods [20]; increases in temperature during summer months affect their development cycle, including the speed of development of their aquatic phases, their rates of egg production and in extending their period of activity. It is expected therefore that an increase in temperature would increase numbers of active biting arthropods. Many biting arthropods (e.g. mosquitoes) have an aquatic immature phase so it is possible that increases in bites could be expected following increases in precipitation. However, the impact of precipitation on arthropods varies between species groups, and even in the case of mosquitoes their abundance can be determined by the degree of water storage, and therefore be independent of precipitation. What is consistent though across all insects is the impact that changing temperature has on their seasonality, development, and in the case of haematophagous insects, their gonotrophic cycle.

One of the key challenges in vector-borne disease surveillance and research is developing an understanding of the impacts of climatic change, and particularly the effects of extreme weather events on vectors. Understanding these interactions, and developing a baseline of reports, using a long-term dataset, is crucial in predicting increases in nuisance biting, which can have direct relevance to disease transmission. This is the first time that robust baselines for arthropod bites have been produced across multiple realtime surveillance systems for England. Although codes for a variety of different arthropod bites/stings have been available in these health systems, the creation and utilization of a real-time indicator for syndromic surveillance has enabled data to be routinely collated, analysed and fed back into the public health system. Now these baselines are in place they can be monitored routinely and in real-time to allow early alerting of increases in arthropod bites which would enable the early dissemination of timely public health messages. Being able to link the occurrence of a bite with the seeking of healthcare also provides an indication of burden on the healthcare services.

These baselines have further utility in identifying new emerging vectors and in monitoring the impact of climatic events such as flooding to help target public health advice and action. It should also be noted that there is also a role for these baselines in reassurance of no impact on public health. These indictors can also be used to inform the development and monitoring of national acute heatwave plans and preparedness and response to future extreme weather events and climate change. We are unaware of any significant events captured in these baselines that would affect this utility.

We found that arthropod-bite incidence rates estimated from the RCGP system were lower than those previously found in a study undertaken in England and Wales during 1999-2003 [10]. This may be due to the two studies examining different time periods and therefore resulting in different samples but also due to comparing median with mean incidence. Incidence in our study was also lower than that found in Switzerland but this would be expected as there is a different climate and habitats to England and estimates from this study cannot be generalized to other countries [9]. Significant differences in arthropod bite incidence were observed by sex, with females being significantly more likely to attend for an arthropod bite GP consultation (both in-hours and out-of-hours) than males. This is consistent with a previous study in the UK which hypothesized that females may be at more risk of an arthropod bite due to different clothing, e.g. arms and legs more exposed, particularly in summer months and increased use of fragrances from perfumes and lotions which may attract arthropods [21]. Although it should be noted that across many syndromic indicators in these systems, female patients are found to consult more than males and this finding could simply reflect this. For the NHS Direct system, the opposite was found with the proportion of calls made for arthropod bites being significantly higher for males than female. This could be a reflection of the convenience of remote health systems for men but this has not generally been seen for other indicators in the system. Statistically significant differences in arthropod incidence were observed between age groups across all systems. Incidence was highest in the 45-64 years 
age group in three systems and in the 5-14 years age group in two systems. This is partly consistent with other studies that found incidence of bites to be highest in adults [9-11]. There were significant differences in arthropod bite incidence by PHE region although there were no consistent geographical trends across systems. Geographical variation has been found previously to be due to a number of environmental factors such as proportion of areas covered by woodland, sandy soil, dry uncultivated land and sheep density [12]. Further work should explore the differences by area in England and include subgroup analysis by urban and rural areas, and areas close to freshwater wetlands and coastal marshes so that geographical location can be incorporated into future modelling work.

\section{Limitations of the study}

We acknowledge that extrapolation of the results found in the syndromic surveillance system to the whole English population is a crude estimate. Although these are the best available estimates for England, it makes the assumption that there is a constant rate of arthropod bites across England, which is not the case, and these estimates should be used with care. These estimates and the regression model also did not take into account gender, age or region. Age and sex standardization would have provided more robust estimates although there was no clear pattern as to which region had the highest incidence across all systems, which needs to be explored further before inclusion in the models.

We also acknowledge that the incidence of arthropod bites found in this study will underestimate the true population burden as the majority of arthropod bites are likely to be treated at home and only those cases that experience a more severe reaction may present to healthcare services. Our study used data collated at the healthcare unit level, e.g. GPs and EDs and so may also be subject to ecological fallacy. Information on the total number of GP consultations per week in England was not available, therefore this incidence was unable to be presented as a percentage as with the other data sources.

We hypothesize that a variety of arthropods are responsible for the seasonal biting found in this study (Table 1, Fig. 2). However, the clinical diagnosis coding in the majority of systems was broad so bites and stings from individual arthropod species could not be differentiated to ascertain which species causes the greatest public health burden. Data were also limited on arthropod activity to be able to investigate further the association with the arthropod bite indicators and temperature. Tick activity was the most extensive arthropod data available for inclusion in this study [22] but due to the arthropod bite indicator including bites and stings from a broad range of arthropods, it is thought ticks only make up a small part of this public health burden. Furthermore ticks tend be active more in the spring months (March-June) and again in autumn as they are less active in high temperatures.

Other limitations of our study include the possibility that coding errors may have resulted in the inclusion of a small number of non-insect bites and we were unable to identify and remove arthropod bites that were acquired outside England or travel associated. There are climatic influences on arthropod ecosystems such as humidity and precipitation, as well as influences on people's health-seeking behaviour that may explain the association found that have not been taken account of in our study. This is evident in Figure 2 where temperature does not fully explain the spike in arthropod incidence in 2004 or the dip in 2011. Full weather pattern information, including routine precipitation data was not accessible at the time of this study to explore differences seen between years or other variables that could explain these peaks. Applying such data to a range of insect groups with differing requirements for an aquatic habitat can also be problematic, as described above. Future work is planned to further explore the association found with temperature, for example trends and seasonality, and ascertain other factors that may predict arthropod bite activity which can be used in modelling the impact of climate change.

We have shown that real-time syndromic surveillance systems can be used to monitor the incidence of arthropod bites. Our study has provided an estimate of the incidence of arthropod bites in England and baselines are now in place to be used for future routine monitoring and to assess any changes in arthropod biting due to extreme events and climate change.

\section{ACKNOWLEDGEMENTS}

We acknowledge the members of PHE ReSST for providing data, Andre Charlett for additional statistical advice and Obaghe Edeghere and Sam Bracebridge from the Field Epidemiology Training Programme for their support, advice and comments on this manuscript. We acknowledge support from: NHS Direct; Royal College of Emergency Medicine, EDs participating in 
the emergency department system (EDSSS), EMIS Health and L2S2 Ltd; out-of-hours providers submitting data to the GPOOHSS and Advanced Heath \& Care; TPP and participating SystmOne practices and University of Nottingham, ClinRisk, EMIS Health and EMIS practices submitting data to the QSurveillance database and practices contributing to the RCGP Research and Surveillance network. The authors receive support from several relevant National Institute for Health Research Health Protection Research Units, all in partnership with Public Health England (PHE), specifically: Environmental Change and Health at the London School of Hygiene \& Tropical Medicine, in collaboration with the University of Exeter, University College London, and the Met Office (J.M.); Emerging Infections and Zoonoses at the University of Liverpool and Liverpool School of Tropical Medicine (J.M., S.L.); Emergency Preparedness \& Response at King's College London, in partnership with University of East Anglia and Newcastle University (A.E., R.M., G.S., S.L.). The views expressed are those of the authors and not necessarily those of the National Health Service, the NIHR, the Department of Health, or PHE.

This work did not receive any external funding and was supported through core surveillance funding by PHE.

\section{DECLARATION OF INTEREST}

None.

\section{REFERENCES}

1. Steen CJ, Carbonaro PA, Schwartz RA. Arthropods in dermatology. Journal of the American Academy of Dermatology 2004; 50: 819-842.

2. Anon. Management of simple insect bites: where's the evidence? Drug and Therapeutics Bulletin 2012; 50: 45-48.

3. Landolt B, et al. Skin disorders encountered in a Swiss pediatric emergency department. Swiss Medical Weekly 2013; 143: w13731.

4. Clark S, et al. Multicenter study of emergency department visits for insect sting allergies. Journal of Allergy and Clinical Immunology 2005; 116: 643-649.

5. Peng MM, Jick H. A population-based study of the incidence, cause, and severity of anaphylaxis in the United Kingdom. Archives of Internal Medicine 2004; 164: 317-319.
6. Vardoulakis S, Heaviside C. Health Effects of climate change in the UK 2012. London: Health Protection Agency, 2012.

7. Medlock JM. Impacts of climate change on vectorborne disease in the UK. Chemical Hazards \& Poisons Report 2011; 19: 33-37.

8. Medlock JM, et al. Mosquito nuisance and control in the UK. European Mosquito Bulletin 2012; 30.

9. Altpeter E, et al. Tick related diseases in Switzerland, 2008 to 2011. Swiss Medical Weekly 2013; 143: w13725.

10. Elliot AJ, et al. The association between impetigo, insect bites and air temperature: a retrospective 5-year study (1999-2003) using morbidity data collected from a sentinel general practice network database. Family Practice 2006; 23: 490-496.

11. Hjetland R, et al. Tick bites in healthy adults from western Norway: occurrence, risk factors, and outcomes. Ticks and Tick-borne Diseases 2013; 4: 304-310.

12. de Mik EL, et al. The geographical distribution of tick bites and erythema migrans in general practice in The Netherlands. International Journal of Epidemiology 1997; 26: 451-457.

13. den Boon S, et al. Doubling of the number of cases of tick bites and lyme borreliosis seen by general practitioners in the Netherlands [in Dutch]. Nederlands Tijdschrift voor Geneeskunde 2004; 148: 665-670.

14. Department of Health. Health Protection Legislation (England) Guidance, 2010 (http://webarchive.nationalarchives.gov.uk/20130107105354/http://www.dh.gov.uk/ prod_consum_dh/groups/dh_digitalassets/@dh/@en/@ps/ documents/digitalasset/dh_114589.pdf).

15. Triple S Project. Assessment of syndromic surveillance in Europe. Lancet 2011; 378: 1833-1834.

16. Elliot AJ, et al. Syndromic surveillance - a public health legacy of the London 2012 Olympic and Paralympic Games. Public Health 2013; 127: 777-781.

17. Fleming DM. Weekly Returns Service of the Royal College of General Practitioners. Communicable Disease and Public Health 1999; 2: 96-100.

18. Parker DE, Legg TP, Folland CK. A new daily Central England Temperature series, 1772-1991. International Journal of Climatology 1992; 12: 317-342.

19. Morbey RA, et al. Development and refinement of new statistical methods for enhanced syndromic surveillance during the 2012 Olympic and Paralympic Games. Health Informatics Journal 2014.

20. Roy HE, et al. Nuisance insects and climate change. London: Department for Environment, Food and Rural Affairs, 2009.

21. Foster WA, Hancock RG. Nectar related olfactory and visual attractants for mosquitoes. Journal of the American Mosquito Control Association 1994; 10: 288-296.

22. Jameson LJ, Medlock JM. Tick surveillance in Great Britain. Vector-Borne and Zoonotic Diseases 2011; 11: 403-412. 